\title{
The prevalence of self-reported underuse of medications due to cost for the elderly: results from seven European urban communities
}

Aurima Stankuniene ${ }^{1 *}$, Mindaugas Stankunas ${ }^{2}$, Mark Avery $^{3}$, Jutta Lindert ${ }^{4,5}$, Rita Mikalauskiene ${ }^{1}$, Maria Gabriella Melchiorre ${ }^{6}$, Francisco Torres-Gonzalez ${ }^{7}$, Elisabeth loannidi-Kapolou ${ }^{8}$, Henrique Barros ${ }^{9}$, Arūnas Savickas ${ }^{1}$, Raimondas Radziunas ${ }^{1}$ and Joaquim J. F. Soares ${ }^{10}$

\begin{abstract}
Background: The aim of this study was to evaluate the prevalence of self-reported underuse of medications due to procurement costs amongst older persons from seven European urban communities.

Methods: The data were collected in a cross-sectional study ("ABUEL, Elder abuse: A multinational prevalence survey") in 2009. Randomly selected people aged 60-84 years $(n=4,467)$ from seven urban communities: Stuttgart (Germany), Athens (Greece), Ancona (Italy), Kaunas (Lithuania), Porto (Portugal), Granada (Spain) and Stockholm (Sweden) were interviewed. Response rate $-45.2 \%$. Ethical permission was received in each country.

Results: The results indicate that $3.6 \%(n=162)$ of the respondents self-reported refraining from buying prescribed medications due to cost. The highest prevalence of this problem was identified in Lithuania $(15.7 \%, n=99)$ and Portugal $(4.3 \%, n=28)$. Other countries reported lower percentages of refraining from buying medications (Germany - $2.0 \%$, Italy $-1.6 \%$, Sweden $-1.0 \%$, Greece $-0.6 \%$, Spain - $0.3 \%$ ). Females refrained more often from buying medications than males ( $2.6 \%$ vs. $4.4 \%, p<0.0001)$. The prevalence of this refraining tended to increase with economic hardship.

Discussion: These differences between countries can be only partly described by the financing of health-care systems. In spite of the presence of cost reimbursement mechanisms, patients need to make co-payments (or in some cases to pay the full price) for prescribed medications. This indicates that the purchasing power of people in 10.1186/s12913-0151089-4 the particular country can play a major role and be related with the economic situation in the country. Lithuania, which has reported the highest refrain rates, had the lowest gross domestic product (at the time of conducting this study) of all participating countries in the study.
\end{abstract}

Conclusions: Refraining from buying the prescribed medications due to cost is a problem for women and men in respect to ageing people in Europe. Prevalence varies by country, sex, and economic hardship.

Keywords: Ageing, Accessibility, Medications, Europe, ABUEL

\section{Background}

The use of medicines by elderly people is a growing concern in social pharmacy and beyond [1, 2]. In particular, polypharmacy (the use of multiple medications) is common among the elderly but it may cause many problems such as an increased risk of inappropriate use of medications/drugs, adverse effects and non-adherence. In addition,

\footnotetext{
* Correspondence: aurimastan@gmail.com

'Department of Drug Technology and Social Pharmacy, Lithuanian University of Health Sciences, Kaunas, Lithuania

Full list of author information is available at the end of the article
}

polypharmacy increases medical costs [3]. Moreover, increasing prices and the proportion of out-of-pocket payments in purchasing necessary pharmaceuticals may lead to situations where some older people refrain from buying prescribed medications [4]. The World Health Organization (WHO) has indicated five broad groupings of potential reasons for medication nonadherence: 1) patient, 2) health condition, 3) therapy, 4) socio-economic and 5) health system-related factors. In particular socio-economic reasons include low health literacy, poor social support and higher medication costs [5]. A 
review by Perkins (2002) showed that the correlation of poor adherence were as follows: patients' beliefs about their illness/benefits of treatment, and barriers to treatment such as easy access to treatment, family/social support and perceived costs of treatment [6].

This non-adherence to medication use may cause serious problems to the health status of patients and increased cost to health-care systems in terms of additional hospital admissions. For instance, data from Australia suggest that at least 45,000 older Australians are hospitalized each year because of medication-related problems, representing 20-30\% of unplanned hospital admissions for this age group [7]. Non-adherence due to costs in the elderly, could be of a significant and worrying size problem in European countries. There have been several attempts to measure the size of this problem in European countries and beyond [8]. However, we still lack comparable data on the refraining of purchasing medications due to cost.

In this paper we use data from a cross sectional study in seven European countries ("Elder abuse: a multinational prevalence study - ABUEL" [9] project. One of the objectives of this project was to measure the accessibility and use of health services by older people. The present study is an opportunity to provide reliable data on the issue. Basic characteristics of the healthcare system and pharmaceutical schemes in each country are presented in Table 1 [10-18]. Some papers on use and non-adherence have been published elsewhere [19-22]. However, the referred papers have examined the prevalence of refrain due to any cause [19], or focused on the situation in Lithuania [20-22]. In this paper, we investigate the prevalence of refrain due to financial problems among older persons and to compare it among seven European urban communities.

\section{Methods}

Data for this study were collected during the European project ABUEL. The participants consisted of randomly selected women and men from the general population living in urban centres of seven European countries (Germany; Stuttgart; Greece, Athens; Italy, Ancona; Lithuania, Kaunas; Portugal, Porto; Spain, Granada; Sweden, Stockholm), except for Greece where a random route sample was used. Inclusion criteria were: 1 ) aged 60-84 years; 2) did not suffer from dementia or other cognitive impairments; 3 ) had a legal status (national citizens or documented migrants); 4) lived in the community or sheltered houses; 5) could read and write in the native languages; and 6) accepted participation to the study. A sample size was calculated based on municipal censuses (women and men aged 60-84 years) and an expected abuse prevalence of $13 \%$ derived from a recent systematic review [23]. The sample size was customized for each country according to the population of individuals aged $60-84$ years, with a maximum of 642 individuals in each of the participating countries because of the infinite population assumption. The sample was calculated proportional to age-sex groups in the population in each city. Three sampling approaches were used in ABUEL: 1) registrybased sampling (Germany, Spain, Italy, Lithuania and Sweden); 2) sampling by random route (Greece); and 3) cluster sampling (Portugal). The registry-based sampling was based on the city's population registries.

The total number of participants amounted to 4,451 (2,576 women, $57.9 \%)$. Response rates in the sampling base varied between countries from 18.9-87.4 \%, with a mean of $45.2 \%$ across countries. Response rates for women were $47.1 \%$ and for men $49.3 \%$, and varied between age groups from $47.0-49.7 \%$, with a mean of $48 \%$ across age groups. ${ }^{1}$ However, there were no major differences (age and gender) between refusals and nonrefusals nor did they differ from the general population in each participating country. The final sample consisted of 4,467 persons (2,559 women, $57.3 \%$ ). A more detailed description of sampling, data collection, and study limitations are described in a separate ABUEL methodology paper [24].

The design of the study was cross-sectional. Recruitment and data gathering were performed during January-July, 2009. Written information about the ABUEL study was sent to the eligible individuals' homes. Trained interviewers telephoned the eligible persons (except in Lithuania) and provided information about the study. Informed consent from participants was obtained before interviewing. Two administration modes were used: (i) face-to-face interviews (Spain, Italy, Greece, Lithuania, Portugal); and (ii) mixed methods, i.e. face-to-face interviews and mailed questionnaires (Germany and Sweden).

Great emphasis was put on confidentiality, anonymity and the rights of older persons. The ethical permissions for the project were given by: Germany, Ethikkommission des Landes Baden-Wuerttenberg; Italy, Bioethics Advisory Committee of National Institute of Health and Science on Aging, Italian National Institute of Health and Science on Aging; Lithuania, The Lithuanian State Data Protection Inspectorate and the Kaunas Regional Bioethics Committee; Portugal, Comité de Ética do Hospital de João; Spain, Comité de Etica en Investigación de la Universidad de Granada; and Sweden, Regional Ethical Committee at Karolinska Institutet. In Greece, QED (market research company) conducted the fieldwork under the codes and guidelines of International Chamber of Commerce/European Society for Opinion and Market Research which are similar to ethical provisions in the other participating countries.

The participants completed a standardized questionnaire with various scales and questions [25]. Self-reported refrain 
Table 1 Basic characteristics of the healthcare system and pharmaceutical schemes in ABUEL study countries

\begin{tabular}{|c|c|c|c|c|c|c|c|}
\hline Indicator & Lithuania & Sweden & Germany & Italy & Spain & Portugal & Greece \\
\hline \multirow{2}{*}{$\begin{array}{l}\text { Total health } \\
\text { expenditure } \\
2011 \text { as \% of } \\
\text { GDP (PPP\$ per } \\
\text { capita) }^{1}\end{array}$} & $6.66 \%$ & $9.62 \%$ & $11.28 \%$ & $9.18 \%$ & $9.62 \%$ & $9.46 \%$ & $9.28 \%$ \\
\hline & (1426 PPP\$) & (4158 PPP\$) & (4617 PPP\$) & (3040 PPP\$) & (3145 PPP\$) & (2400 PPP\$) & (2347 PPP\$) \\
\hline $\begin{array}{l}\text { Total } \\
\text { pharmaceutical } \\
\text { expenditure as } \% \\
\text { of total health } 2011^{1}\end{array}$ & 24.9 & 12.1 & 14.1 & 16.2 & 17.4 & 17.9 & 28.5 \\
\hline $\begin{array}{l}\text { Public } \\
\text { pharmaceutical } \\
\text { expenditure as } \% \\
\text { of total pharmaceutical } \\
\text { expenditure } 2011^{1}\end{array}$ & 34.2 & 58.3 & 75.6 & 46.6 & 71.0 & 55.1 & 73.7 \\
\hline $\begin{array}{l}\text { Predominant health } \\
\text { care financing mechanism² }\end{array}$ & Social insurance & Taxes (local) & Social insurance & Taxes (local) & Taxes (local) & Taxes (central) & Social insurance \\
\hline $\begin{array}{l}\text { Reimbursment mechanism } \\
\text { for prescribed medicines }\end{array}$ & $\begin{array}{l}\text { NHIF reimbursed } \\
50-100 \% \text { of price } \\
\text { of selected } \\
\text { medicines }^{3}\end{array}$ & $\begin{array}{l}\text { The patient has } \\
\text { to pay the full cost } \\
\text { for prescribed drugs, } \\
\text { up to SEK } 1100(€ 122) \text {, } \\
\text { after which level the } \\
\text { subsidy gradually } \\
\text { increase up to a } 100 \%{ }^{4}\end{array}$ & $\begin{array}{l}\text { For prescription- } \\
\text { only drugs, } \\
\text { pharmacists are } \\
\text { now paid through } \\
\text { a flat-rate payment } \\
\text { of } € 8.35 \text { plus a fixed } \\
\text { margin of } 3 \% \text {. } \\
\text { The retail price } \\
\text { contains an } \\
\text { additional } 19 \% \\
\text { VAT. }^{5}\end{array}$ & $\begin{array}{l}\text { Only Class A } \\
\text { medicines are } \\
\text { partially reimbursed } \\
\text { by the SSN and involve } \\
\text { a modest co-payment } \\
\text { that varies across regions. }{ }^{6} \\
\text { I.e. Veneto Region implies } \\
\text { co-payment mechanism } \\
\text { from } € 2 \text { for each packet } \\
\text { up to a maximum of } € 4 \\
\text { for each prescription. }\end{array}$ & $\begin{array}{l}\text { Medical } \\
\text { prescriptions } \\
\text { funded by } \\
\text { the SNS are } \\
\text { exempt from } \\
\text { co-payment for } \\
\text { pensioners and } \\
\text { their beneficiaries. } \\
\text { nonpensioners and } \\
\text { their beneficiaries } \\
\text { pay } 40 \% \text { of the } \\
\text { retail price. }\end{array}$ & $\begin{array}{l}\text { There are four groups } \\
\text { of medications and } \\
\text { reimbursment varies } \\
\text { by these categories } \\
\text { from } 90 \% \text { for category } \\
\text { A to } 5 \% \text { for category D. } \\
\text { Pensioners have additional } \\
\text { reductions from } 5 \text { to } 15 \%{ }^{9}\end{array}$ & $\begin{array}{l}\text { Insured citizens participate } \\
\text { in covering the cost of } \\
\text { pharmaceuticals with a } \\
\text { co-payment rate set at } \\
25 \% \text {. Patients with chronic } \\
\text { conditions are exempted } \\
\text { from co-payments, while } \\
\text { pensioners on lower } \\
\text { incomes who are } \\
\text { beneficiaries of EKAS pay } \\
\text { a co-payment of } 10 \% \text {. The } \\
\text { very poor are entitled to } \\
\text { pharmaceuticals provided } \\
\text { by public hospitals free of } \\
\text { charge. }\end{array}$ \\
\hline
\end{tabular}

Surce: ${ }^{1}$ - Ref. $10 i^{2}$ - Ref. $11 i^{3}-$ Ref. $12 i^{4}$ - Ref. $13 ;^{5}$ - Ref. $14 i^{6}$ - Ref. $15 i^{7}$ - Ref. $16 i^{8}$ - Ref $17,^{9}$ - Ref 18

GDP Gross Domestic Product, PPP Purchasing Power Parity, NHIF National Health Insurance Fund (Lithuania), SSN Italy's National Health Service, SNS Spanish national health system, EKAS Social Solidarity Benefit for low-income pensioners 
from buying prescribed medications due to costs was measured with question: "What were the reasons for not buying prescribed medications and care"? (multiple-choice). A specific time frame has not identified. Economic hardship was measured with one question "How often are you worried about the daily expenses? (e.g. for buying food)" in a "never/ quite often/often/always" format. A participant was defined as having "financial strain" if she/he chose any response other than "never".

Data were computed, coded and analyzed using the Statistical Package for the Social Sciences for Windows, Version 17.0 (SPSS Inc.). The following statistical analyses were applied: 1) descriptive statistics; 2) logistic regression.

Associations of the reported refrain from buying prescribed medications due to costs and social-economic factors were measured calculating the prevalence of nonadherence. Differences between groups were assessed by using the two-tailed $\mathrm{z}$ criteria for categorical variables.

For evaluation of the impact of explanatory variables on analyzed event, (binary dependent variable) Enter model of multivariate logistic regression was used. Dependent variable was the reported refrain from buying prescribed medications due to costs (based on answers in the questionnaire). Sex, age, country of residence, living alone, education, economic hardship were used as independent variables. These associations were measured using odds ratio (OR) and calculating the $95 \%$ confidence interval $(\mathrm{CI})$. Differences in results at the $p<0.05$ level were considered statistically significant.

\section{Results}

Of the 4,467 respondents, 1,908 (42.5\%) were male and 2,559 (57.5\%) were female. The distribution of respondents by age was: 60-64 years (25.2\%), 65-69 years (24.4\%), 70-74 years (21.1\%), 75-79 years (16.1\%) and $80-84$ years (12.2\%); and by education: cannot read/ write $(3.1 \%)$, without any degree $(4.2 \%)$, less than primary school $(7.5 \%)$, primary school/similar (24.4\%), secondary school/similar (40.0\%), university/similar $(19.2 \%)$ and other (1.6\%) (Table 2). A more detailed description of the study sample is presented in a separate paper [26].

The results indicate that $3.6 \%$ of all respondents of the study had refrained from buying the prescribed medications due to cost. Furthermore, prevalence varied by country (Fig. 1). Cost-related non-adherence has been

Table 2 The main socio-demographic characteristics of respondents

\begin{tabular}{|c|c|c|c|c|c|c|c|c|}
\hline \multirow[t]{2}{*}{ Variable } & \multicolumn{8}{|l|}{$\% / n$} \\
\hline & Lithuania & Sweden & Germany & Italy & Spain & Portugal & Greece & All countries \\
\hline \multicolumn{9}{|l|}{ Sex } \\
\hline Male & $35.7 / 225$ & $46.8 / 293$ & $47.1 / 305$ & $43.0 / 270$ & $42.8 / 272$ & $39.0 / 256$ & $44.6 / 287$ & $42.7 / 1908$ \\
\hline Female & $64.3 / 405$ & $53.2 / 333$ & $52.9 / 343$ & $57.0 / 358$ & $57.2 / 364$ & $61.0 / 400$ & $55.4 / 356$ & $57.3 / 2559$ \\
\hline \multicolumn{9}{|l|}{ Age group } \\
\hline 60-64 years & $23.2 / 146$ & $33.9 / 212$ & $21.7 / 137$ & $22.5 / 141$ & 23.3/148 & $24.5 / 161$ & 27.8/179 & $25.2 / 1124$ \\
\hline $65-69$ years & $23.5 / 148$ & 23.8/149 & $28.4 / 184$ & $22.6 / 142$ & $22.0 / 140$ & $24.4 / 160$ & $25.7 / 165$ & $24.4 / 1088$ \\
\hline $70-74$ years & $23.2 / 146$ & 16.9/106 & 23.5/152 & $20.5 / 129$ & $22.5 / 143$ & 21.0/138 & $22.9 / 147$ & $21.5 / 961$ \\
\hline 74-79 years & $19.2 / 121$ & $13.3 / 83$ & $16.0 / 104$ & 18.9/119 & $17.8 / 113$ & $17.5 / 115$ & $14.6 / 94$ & $16.8 / 749$ \\
\hline $80-84$ years & $11.0 / 69$ & $12.1 / 76$ & $11.0 / 71$ & $15.4 / 97$ & $14.5 / 92$ & $12.5 / 82$ & $9.0 / 58$ & $12.2 / 545$ \\
\hline \multicolumn{9}{|l|}{ Lives alone } \\
\hline No & $75.8 / 475$ & $66.1 / 414$ & $67.3 / 429$ & $86.9 / 546$ & $82.14 / 522$ & $78.4 / 514$ & $73.7 / 474$ & $75.8 / 3374$ \\
\hline Yes & $24.2 / 152$ & $33.9 / 212$ & $32.7 / 208$ & $13.1 / 82$ & $17.9 / 114$ & $21.6 / 142$ & $26.3 / 169$ & $24.2 / 1079$ \\
\hline \multicolumn{9}{|l|}{ Education } \\
\hline Less than primary & $5.6 / 34$ & $2.3 / 14$ & $1.3 / 8$ & $4.3 / 27$ & $60.0 / 381$ & $11.4 / 75$ & 19.0/122 & $15.1 / 661$ \\
\hline Primary & $24.3 / 147$ & $31.1 / 193$ & $2.2 / 13$ & $34.6 / 217$ & $13.1 / 83$ & $36.4 / 239$ & $31.2 / 200$ & 24.9/1092 \\
\hline Secondary & $46.7 / 283$ & $33.3 / 207$ & $67.2 / 405$ & $50.3 / 316$ & $11.5 / 73$ & $36.1 / 237$ & $40.7 / 261$ & 40.6/1782 \\
\hline University & $23.4 / 142$ & $33.3 / 207$ & $29.4 / 177$ & $10.8 / 68$ & $15.4 / 98$ & $16.0 / 105$ & $9.0 / 58$ & $19.5 / 855$ \\
\hline \multicolumn{9}{|l|}{ Economic hardship } \\
\hline Never & $26.8 / 169$ & $64.0 / 400$ & $52.5 / 339$ & $41.4 / 259$ & $31.8 / 202$ & 29.7/195 & $6.4 / 41$ & $36.0 / 1605$ \\
\hline Quite often & $37.8 / 238$ & $26.4 / 165$ & $31.7 / 205$ & $35.8 / 224$ & $9.9 / 63$ & $23.0 / 151$ & $23.5 / 151$ & 26.8/1197 \\
\hline Often & $21.4 / 135$ & $5.4 / 34$ & $11.5 / 74$ & $15.3 / 96$ & $15.1 / 96$ & $11.3 / 74$ & $28.1 / 181$ & $15.5 / 690$ \\
\hline Always & $14.0 / 88$ & $4.2 / 26$ & $4.3 / 28$ & $7.5 / 47$ & $43.2 / 275$ & $36.0 / 236$ & $42.0 / 270$ & $21.7 / 970$ \\
\hline
\end{tabular}




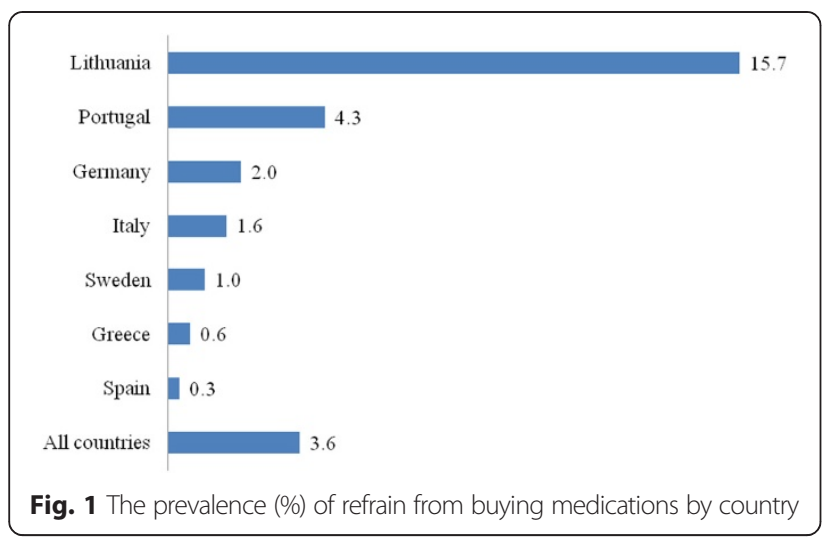

identified in Lithuania $15.7 \%(n=99)$. The other countries reported considerably lower rates. The second highest rate was in Portugal $(4.3 \%, n=28)$. The remaining countries had prevalence rates lower than $2 \%$.

The prevalence of self-reported refrain from buying medications was evaluated by different socio-economic factors in each country and study sample in general (Table 3). It was identified, that the prevalence of refrain due to cost has differed by sex and economic hardship. Females and people experiencing economic problems were more likely not to buy prescribed drugs because of costs. Age, education and living alone were not associated with refrain.

A logistic regression was used to estimate the risk factors involved in the occurrence of refrain from buying prescribed medication due to cost (Table 4). The results revealed that being from Lithuania and experiencing economic hardship were related with increased risk to refrain from buying prescribed medications due to cost $(\mathrm{OR}=14.92$ and $\mathrm{OR}=1.99$ respectively $)$.

\section{Discussion}

Our study revealed that the prevalence of refrain was due to financial problems among older persons varied by country from $0.3 \%$ in Spain to $15.7 \%$ in Lithuania. Similar studies from other countries show variations by country as well. The reported underuse of medicines due to costs in older age varies from $3 \%$ in the Australia, Canada, New Zealand, and the Netherlands to $8 \%$ in Germany and $9 \%$ in the United States [8].

Table 3 The prevalence of refrain from buying medications due to cost by different socio-economic variables

\begin{tabular}{|c|c|c|c|c|c|c|c|c|}
\hline \multirow[t]{2}{*}{ Variable } & \multicolumn{8}{|l|}{$\% / n$} \\
\hline & Lithuania & Sweden & Germany & Italy & Spain & Portugal & Greece & All \\
\hline \multicolumn{9}{|l|}{ Sex } \\
\hline Male (R) & $16.0 / 36$ & $0.7 / 2$ & $1.6 / 5$ & $0.7 / 2$ & $0.0 / 0$ & $1.6 / 4$ & $0.0 / 0$ & $2.6 / 49$ \\
\hline Female & $15.6 / 63$ & $1.2 / 4$ & $2.3 / 8$ & $2.2 / 8$ & $0.5 / 2$ & $6.0 / 24^{* *}$ & $1.1 / 4^{*}$ & $4.4 / 113^{* * *}$ \\
\hline \multicolumn{9}{|l|}{ Age group } \\
\hline $60-64$ years $(R)$ & $20.5 / 30$ & $2.4 / 5$ & $2.9 / 4$ & $2.1 / 3$ & $0.0 / 0$ & $1.9 / 3$ & $1.1 / 2$ & $4.2 / 47$ \\
\hline $65-69$ years & $16.9 / 25$ & $0.0 / 0^{*}$ & $0.5 / 1$ & $2.1 / 3$ & $0.7 / 1$ & $3.8 / 6$ & $0.6 / 1$ & $3.4 / 37$ \\
\hline 70-74 years & $12.3 / 18$ & $0.9 / 1$ & $3.9 / 6$ & $2.3 / 3$ & $0.0 / 0$ & $5.8 / 8$ & $0.7 / 1$ & $3.9 / 37$ \\
\hline 74-79 years & $14.0 / 17$ & $0.0 / 0^{*}$ & $1.0 / 1$ & $0.8 / 1$ & $0.9 / 1$ & $7.0 / 8$ & $0.0 / 0$ & $3.7 / 28$ \\
\hline 80-84 years & $13.0 / 9$ & $0.0 / 0^{*}$ & $1.4 / 1$ & $0.0 / 0$ & $0.0 / 0$ & $3.7 / 3$ & $0.0 / 0$ & $2.4 / 13^{*}$ \\
\hline \multicolumn{9}{|l|}{ Lives alone } \\
\hline No (R) & $16.4 / 78$ & $0.7 / 3$ & $0.9 / 4$ & $1.5 / 8$ & $0.2 / 1$ & $3.3 / 17$ & $0.6 / 3$ & $3.4 / 114$ \\
\hline Yes & $13.2 / 20$ & $1.4 / 3$ & $4.3 / 9^{*}$ & $2.4 / 2$ & $0.9 / 1$ & $7.7 / 11$ & $0.6 / 1$ & $4.4 / 47$ \\
\hline \multicolumn{9}{|l|}{ Education } \\
\hline Less than primary & $26.5 / 9$ & $7.1 / 1$ & $0.0 / 0$ & $0.0 / 0$ & $0.3 / 1$ & $17.3 / 13^{* * *}$ & $0.0 / 0$ & $3.6 / 24$ \\
\hline Primary & $17.7 / 26$ & $1.6 / 3$ & $7.7 / 1$ & $0.9 / 2$ & $1.2 / 1$ & $4.2 / 10$ & $0.5 / 1$ & $4.1 / 45$ \\
\hline Secondary & $16.3 / 46$ & $1.0 / 2$ & $2.2 / 9$ & $2.2 / 7$ & $0.0 / 0$ & $1.3 / 3$ & $0.8 / 2$ & $3.8 / 68$ \\
\hline University (R) & $11.3 / 16$ & $0.0 / 0$ & $1.7 / 3$ & $1.5 / 1$ & $0.0 / 0$ & $1.9 / 2$ & $0.0 / 0$ & $2.6 / 22$ \\
\hline \multicolumn{9}{|l|}{ Economic hardship } \\
\hline Never & $3.0 / 5^{* * *}$ & $0.3 / 1^{*}$ & $0.0 / 0^{*}$ & $0.8 / 2^{*}$ & $0.0 / 0$ & $0.0 / 0^{* * *}$ & $2.4 / 1$ & $0.6 / 9^{* * *}$ \\
\hline Quite often & $15.1 / 36^{*}$ & $0.0 / 0^{*}$ & $2.0 / 4^{*}$ & $0.4 / 1^{*}$ & $0.0 / 0$ & $2.0 / 3^{*}$ & $0.0 / 0$ & $3.7 / 44^{*}$ \\
\hline Often & $24.4 / 33$ & $2.9 / 1$ & $5.4 / 4$ & $2.1 / 2$ & $0.0 / 0$ & $13.5 / 10$ & $0.0 / 0$ & $7.2 / 50$ \\
\hline Always (R) & $28.4 / 25$ & $15.4 / 4$ & $17.9 / 5$ & $10.6 / 5$ & $0.7 / 2$ & $6.4 / 15$ & $1.1 / 3$ & $6.1 / 59$ \\
\hline
\end{tabular}


Table 4 Logistic regression analysis of the relation between refrain from buying prescribed medication due to cost and selected socio-economic factors

\begin{tabular}{llll}
\hline Variable & OR & $95 \% \mathrm{Cl}$ & $P$ \\
\hline Being male & 0.80 & $0.55-1.17$ & 0.249 \\
Age (each age group) & 0.88 & $0.77-1.01$ & 0.077 \\
Education (higher level of education) & 0.83 & $0.68-1.01$ & 0.059 \\
Living not alone & 1.29 & $0.87-1.90$ & 0.207 \\
Being from Lithuania & 14.92 & $10.33-21.56 \quad 1.68-2.35$ & $P<0.001$ \\
Daily worries about expenses (each group of more intensive worries) & 1.99 & 0.001 \\
\hline
\end{tabular}

$p$ significance level, $O R$ odds ratio, $\mathrm{Cl}$ confidence interval

How can these differences between ABUEL countries be explained? It is noteworthy that all countries which have participated in the study had pharmaceutical benefit schemes. This suggests that the financing of healthcare systems can only partly explain differences in refraining from buying prescribed medications among older people. In spite of the presence of cost reimbursement mechanisms, patients need to make copayments (or in some cases to pay the full price) for prescribed medications. In addition, studies indicate that chronic diseases require significant proportions of household incomes for buying medications [27]. This indicates that the purchasing power of people in the particular country can play a major role and be related with the economic situation in the country. Lithuania, which has reported the highest refrain rates, had the lowest gross domestic product (at the time of conducting this study) of all participating countries in the study [28]. It could be that economic factors influenced Lithuanians in deciding not to use prescriptions prescribed by their doctors. It is noteworthy that data for this study were collected during the economic crisis in Lithuania. In 2009, Lithuania experienced one of the highest annual decline of gross domestic product in the European Union (-14.8\%) [29]. This "free fall" of economy caused dramatic changes in salary policies, financing of health care and growth of unemployment [30]. It might be that "hard times" could have a negative impact on the economic accessibility to medications as well. On the other hand, it should be mentioned that the Lithuanian Government cut old-age pensions only from the year 2010 [31]. Therefore, we think that the infl uence of crisis on respondents' answers is very limited. However, further investigations on this issue are needed. Moreover, the similar situation has been observed with accesibility to health care services within this age group during the period of economic recession in in Lithuania.

Our results show that the decision not to purchase medications was linked to individuals experiencing financial strain or problems. Similar patterns have been noticed in studies from Australia, Canada, New Zealand, United Kingdom and the United States [8].
We identified that females were more likely to refrain from buying prescribed medications due to costs. An explanation of this pattern could be that women in general report more bodily distress, and more numerous, intense and frequent somatic symptoms than men [32]. This may cause women to use more pharmaceutical products [20] and spend a considerable amount of the household income on them. It could be that women decided not to buy some of these prescribed medications in order to save financial resources. Correa-De-Araujo et al. (2005) showed that there are gender differences in use and expenditure on prescription drugs amongst older adults aged 65+. Overall, women spent about $17 \%$ more than average expenditures by men. Several authors demonstrate evidence that it is critical for older women and men to have proper access to prescribed medicines, particularly women, given the financial vulnerability of the female population [33]. Moreover, Johnell and Parker (2011) state that women and men express themselves differently, report symptoms differently and probably also are treated differently - encounter different behavior - within the healthcare system. Socio-economic status may also play a part, since women, at least elderly women, often have a lower income and educational level than men. Socio-economic status may be linked to expectations, communication skills, how well informed you are about various treatments, what demands you place on healthcare and how you are treated within the healthcare system. It is therefore important to consider socioeconomic status (e.g. education level) in analyses of gender differences, especially among elderly people [34].

The present study reveled inequalities in medication accessibility between different countries and within countries. It suggests a much broader plan of actions for solving this issue. Frost and Reich (2008) has developed a framework to describe the components of access to new health technologies, which can be adapted to accessibility to medications. According to the authors, there are three key components for improved access: availability (addressing both "upstream" issues of product discovery and development and "downstream" challenges of national pharmaceutical supply systems), affordability (sustainable funding 
and low prices), and safe and effective medicine use (rational use, quality and safety) [35]. These key components are affected by "architecture" of pharmaceutical system, which includes financing pharmaceutical workforce, governance, regulations etc. [36]. A complexity of this problem requires political support and sustainability. The recent WHO European policy framework and strategy for the 21st century "Health 2020" reminds about the commitment of WHO and its Member States to ensure universal coverage, including access to high-quality and affordable care and medicines and to eliminate catastrophic and impoverishing payments [37]. Some countries initiate specific activities to achieve these political objectives. Lithuania, which has demonstrated highest prevalence in cost-related non-adherence, has approved the "Lithuanian Health Program 2014-2025" in 2014 [38]. This national health policy emphasizes the importance in reducing health and health care (including accessibility to medications) inequalities in the country. There are several measures considered for this purpose but to name just few, there are: increase of public funding of health care system, strength of pharmaceutical care, use of health technology asseement in developing a list of state reimbursed medicines.

This study has some limitations. The participants (women and men) were recruited from urban centers in seven European countries and results might not be applicable to rural areas. Secondly, non-responders were not investigated. It could be, that those who refrained from buying prescribed medications were much higher among those who refused. Third, some confounding elements have been identified in the questionnaire. The main question of our paper is not asking, exclusively about medicines, but about care as well. This could cause, that answers reflect not only on medications. However, we expect only a minor effect of this factor, as the question is placed in the group of questions related to use of medications. This could lead, that respondents answering this question put more emphasis on mediations, rather other care. The absence of a specific time frame for refrain, could be identified as confounding factor as well. The fourth, the accuracy of the data was dependent on the participants' subjective assessment of their situation. No objective evaluations (e.g. medical records) have been used to corroborate their responses. More detailed discussion on methodology and study limitations are published in a separate paper [24].

\section{Conclusions}

The current study indicates that $3.6 \%(n=162)$ of older people refrained from buying prescribed medications due to cost. Living in Lithuania and financial strain were associated with self-reported underuse of medicines due to cost.
Non-adherence to medication prescribing occurs frequently in Europe and is associated with adverse outcomes and this impacts on patients, care providers and the healthcare system. As Ho et al. have emphasized: "the first step toward improving adherence, there needs to be a broader recognition of the problem of non-adherence, and once identified, simple strategies should be implemented in daily practice to improve adherence" [39].

\section{Endnotes \\ ${ }^{1}$ Greece excluded.}

\section{Competing interests}

The authors declare that they have no competing interests.

\section{Authors' contribution}

AS, MS, RM performed the data analysis and drafted and revised the manuscript. MA, RR, AS contributed in drafting the manuscript. JS, JL, MM, FG, EIK, HB participated in the initial study design, data collection and revision of the article. All authors read and approved the final manuscript.

\section{Authors' information}

Not applicable.

\section{Availability of data and materials}

Not applicable.

\section{Acknowledgments}

We would like to express our appreciation for the financial support by the European Union through the EAHC, which made possible the realization of the project. We extend also our appreciation to the staff of EAHC, and in particular Dr. Guy Dargent, for their help. Furthermore, we would like to express our appreciation to all participating institutions and to the staff involved in ABUEL. Finally, and most of all, all authors appreciate the kindness, efforts and answers of the elderly people who participated in ABUEL.

\section{Funding}

The ABUEL was supported by the Executive Agency for Health and Consumers (EAHC) (Grant No., A/2007123) and participating institutions.

\section{Author details}

'Department of Drug Technology and Social Pharmacy, Lithuanian University of Health Sciences, Kaunas, Lithuania. ${ }^{2}$ Department of Health Management, Lithuanian University of Health Sciences, Kaunas, Lithuania. ${ }^{3}$ Health Service Management Department, Centre for Health Innovation, School of Medicine, Griffith University, Gold Coast, Queensland, Australia. ${ }^{4}$ Department of Public Health, University of Emden, Emden, Germany. ${ }^{5}$ Brandeis University, Waltham, USA. 'Scientific Technological Area, Centre for Socio Economic Research on Ageing, Italian National Institute of Health and Science on Aging (INRCA), Ancona, Italy. ${ }^{7}$ Centro de Investigación Biomedica en Red de Salud Mental (CIBERSAM), University of Granada, Granada, Spain. ${ }^{8}$ Department of Sociology, National School of Public Health, Athens, Greece. ${ }^{9}$ Department of Hygiene and Epidemiology, Faculty of Medicine, University of Porto, Porto, Portugal. ${ }^{10}$ Department of Health Sciences, Section of Public Health Science, Mid Sweden University, Sundsvall, Sweden.

Received: 16 December 2014 Accepted: 21 September 2015 Published online: 26 September 2015

\section{References}

1. Wagner $L$, Wahlberg V, Worning AM. Drug consumption among elderly - a four-year study. Scand J Caring Sci. 1994;8:113-7.

2. Carey IM, De Wilde S, Harris T, Victor C, Richards N, Hilton SR, et al. What factors predict potentially inappropriate primary care prescribing in older people? Analysis of UK primary care patient record database. Drugs Aging. 2008;25:693-706.

3. Hajjar ER, Cafiero AC, Hanlon JT. Polypharmacy in Elderly Patients. Am J Geriatr Pharmacother. 2007;5:345-51. 
4. Piette JD, Hiesler M, Wagner TH. Problems paying out-of-pocket medication costs among older adults with diabetes. Diabetes Care. 2004;27:384-91.

5. World Health Organization. Adherence to Long-Term Therapy: Evidence for Action. Geneva: World Health Organization; 2003.

6. Perkins DO. Predictors of noncompliance in patients with schizophrenia. J Clin Psychiatry. 2002;63:1121-8.

7. Elliott RA. Problems with medication use in the elderly: An Australian perspective. J Pharm Pract Res. 2006;36:58-66.

8. Kemp A, Roughead E, Preen D, Glover J, Semmens J. Determinants of selfreported medicine underuse due to cost: a comparison of seven countries J Health Serv Res Policy. 2010;15:106-14.

9. Soares JFJ, Barros H, Torres-Gonzales F, loannidi-Kapolou E, Lamura J, Lindert J, et al. Abuse and Health Among Elderly in Europe. Kaunas: Lithuanian University of Health Sciences Press; 2010.

10. Health for all data base. World Health Organization, Copenhagen. 2014. http://data.euro.who.int/hfadb/. Accessed 10 Dec 2014.

11. Thomson S, Foubister T, Mossialos E. Financing health care in the European Union: Challenges and policy responses. Copenhagen: European Observatory on Health Systems and Policies; 2009.

12. Murauskiene $L$, Janoniene $R$, Veniute $M$, van Ginneken $E$, Karanikolos $M$. Lithuania: health system review. Health Syst Transit. 2013;15:1-150.

13. Anell A, Glenngård AH, Merkur S. Sweden: Health system review. Health Syst Transit. 2012;14:1-159.

14. Busse R, Blümel M. Germany: health system review. Health Syst Transit. 2014;16:1-296

15. Ferré $F$, de Belvis AG, Valerio L, Longhi S, Lazzari A, Fattore $G$, et al. Italy: Health System Review. Health Syst Transit. 2014;16:1-168.

16. Toniolo F, Mantoan D, Maresso A. Veneto Region, Italy: Health system review. Health Syst Transit. 2012;14:1-138.

17. García-Armesto S, Abadía-Taira MB, Durán A, Hernández-Quevedo C, BernalDelgado E. Spain: Health system review. Health Syst Transit. 2010;12:1-295.

18. Economou C. Greece: Health system review. Health Syst Transit. 2010;12:1-180.

19. Stankunas M, Soares JJF, Viitasara E, Melchiorre MG, Sudin O, TorresGonzalez F, et al. Factors associated with refraining from prescribed medications among older persons. Australas J Aging. 2014;33:E25-30.

20. Stankuniene A, Stankunas M, Avery M, Radziunas R, Soares JJF, Melchiorre $M G$, et al. Use of medications amongst older persons in Kaunas, Lithuania. Cent Eur J Med. 2013;8:855-60.

21. Stankuniene A, Radziunas R, Stankunas M, Soares JF, Baranauskas A, loannidi-

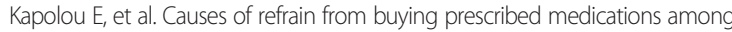
the elderly in Kaunas, Lithuania. Medicina (Kaunas). 2011;47:291-6.

22. Stankuniene A, Stankunas M, Soares JJF, Avery M, Melchiorre MG, TorresGonzalez F, et al. Somatic complaints and refrain from buying prescribed medications. Results from a cross-sectional study on people 60 years and older living in Kaunas (Lithuania). Daru. 2012;20:78.

23. Cooper $C$, Selwood AC, Livingston $G$. The prevalence of elder abuse and neglect: A systematic review. Age Ageing. 2008;37:151-60.

24. Lindert J, Luna J, Torres-Gonzalez F, Barros H, loannidi-Kapolou E, Quattrini S, et al. Study design, sampling and assessment methods of the European study "Abuse of the Elderly in the European Region". Eur J Public Health. 2012;22:662-6

25. ABUEL questionnaire. http://www.abuel.org/docs/pub02_questionnaire.pdf Accessed 21 Nov 2014.

26. Lindert J, de Luna J, Torres-Gonzalez F, Barros H, loannidi-Kopolou E, Melchiorre $M G$, et al. Abuse and neglect of older persons in seven cities in seven countries in Europe: a cross-sectional community study. Int J Public Health. 2013;58:121-32.

27. Rogowski J, Lillard LA, Kington R. The financial burden of prescription drug use among elderly persons. Gerontologist. 1997;37:475-82.

28. Eurostat. GDP per capita in PPS. http://epp.eurostat.ec.europa.eu. Accessed 25 Nov 2014.

29. Eurostat. Real GDP growth rate - volume. http://epp.eurostat.ec.europa.eu/ portal/page/portal/eurostat/home/. Accessed 28 Nov 28, 2014.

30. Stankunas M, Lindert J, Avery M, Sorensen R. Suicide, recession, and unemployment. Lancet. 2013;9868:721.

31. Tiazkijus $\vee$. Problem of the relationship between labour and social law: theory and practice. Verslo ir teises aktualijos. 2010;5:458-75.

32. Stankunas M, Soares JFJ, Stankuniene A, Melchiorre MG, Torres-Gonzales F, loannidi-Kapolou $E$, et al. Differences in reporting somatic complaints in elderly by education level. Cent Eur J Med. 2013;8:125-31.
33. Correa-De-Araujo R, Miller GE, Banthin JS, Trinh Y. Gender Differences in Drug Use and Expenditures in a Privately Insured Population of Older Adults. J Womens Health (Larchmt). 2005;14:73-81.

34. Johnell K, Parker MG. From women's health to gender medicine - An anthology. Solna: The Swedish Council for Working Life and Social Research (FAS); 2011.

35. Frost $L$, Reich M. Access. How do good health technologies get to poor people in poor countries? Cambridge: Harvard Centre for Population and Development Studies; 2008.

36. Hanson K, Palafox B, Anderson S, Guzman J, Moran M, Shretta R, et al. Pharmaceuticals. In: Merson MH, Black RE, Mills AJ, editors. Global Health diseases, programs, systems, and policies. 3rd ed. Burlington: Jones \& Bartlett Learning; 2012. p. 707-55.

37. Health 2020. A European policy framework and strategy for the 21st century. Geneva: World Health Organization; 2013.

38. Lithuanian Health Programme 2014-2025 (XII-964). Vilnius: Seimas of the Republic of Lithuania; 2014

39. Ho PM, Bryson CL, Rumsfeld JS. Medication Adherence: Its Importance in Cardiovascular Outcomes. Circulation. 2009;119:3028-35.

\section{Submit your next manuscript to BioMed Central and take full advantage of:}

- Convenient online submission

- Thorough peer review

- No space constraints or color figure charges

- Immediate publication on acceptance

- Inclusion in PubMed, CAS, Scopus and Google Scholar

- Research which is freely available for redistribution 